\title{
THE EFFECTIVENESS OF A DIVERSITY AWARENESS TRAINING PROGRAMME
}

\author{
COLETTE CAVALEROS \\ LJ VAN VUUREN \\ DELÉNE VISSER \\ Programme in Industrial Psychology \\ Department of Human Resource Management \\ Rand Afrikaans University
}

\begin{abstract}
The objective of this study was to assess the effectiveness of a diversity awareness training programme. A sample of 382 employees from four different departments within a large accounting firm was used to form the groups of a simulated Solomon four-group design. The impact of a two-day workshop on diversity awareness was assessed using a 68-item questionnaire designed to measure awareness of self, impact of differences, performance management, career development, teamwork, work-family needs, participation, organisational culture, relationship building, and general satisfaction with the organisation. The Minnesota Job Satisfaction Questionnaire (20 items) was included to measure job satisfaction. The results showed no evidence of a statistically significant effect of the diversity awareness training programme.
\end{abstract}

\section{OPSOMMING}

Die doel met hierdie studie was om die effektiwiteit van ' $n$ bewustheid-van-diversiteit opleidingsprogram te bepaal Werknemers uit vier departemente van 'n groot ouditeursfirma het die groepe van 'n gesimuleerde Solomon viergroepontwerp gevorm $(\mathrm{N}=382)$. Die impak van ' $\mathrm{n}$ tweedagwerkwinkel oor bewustheid-van-diversiteit is bepaal met ' $n$ 68-item vraelys wat ontwikkel is om bewustheid van die self, impak van verskille, prestasiebestuur, loopbaanontwikkeling, spanwerk, werk-gesinsbehoeftes, deelname, organisasiekultuur, ontwikkeling van verhoudings, en algemene tevredenheid met die organisasie te meet. Die Minnesota Job Satisfaction Questionnaire (20 items) is ingesluit om werktevredenheid te meet. Geen statisties beduidende effek is vir die bewustheid-vandiversiteit opleidingsprogram gevind nie.

It is widely accepted that the single most valuable asset of any organisation is its human asset. It may be said that only organisations that appreciate their staff as much as their capital resources will succeed in today's marketplace. It is for this reason that the development of human resources is increasingly receiving top priority in the workplace. If human resource professionals are to successfully develop their staff, they have to, amongst other things, take employees' economic, social, and psychological needs into consideration (Editor b, 1995). This is increasingly more difficult to achieve in the South African workplace, which is becoming progressively more diverse as a result of the changing socio-political climate, developments taking place abroad particularly in the USA and UK (Human, 1996), and moral obligation and legislation (Hopkins, 1997).

While diversity in the workplace is not a new phenomenon, organisations are becoming more aware of its value as a potential asset (Miller, 1998). The term "diversity" refers to numerous categories of individual differences, including: population group, culture, gender, spirituality, language disability, sexuality, age (Hopkins, 1997); educational level, skills, functional area of expertise, management styles, tenure, parental status, marital status, family background, vocational interests, career aspirations, geographic differences (Diamante, Reid \& Giglio, 1995); social status, physical and mental conditions (Thomas, 1994); communication styles (Van Eron, 1995); as well as personality attributes, working styles, and organisational departments. To conclude simply, diversity refers to the many different ways in which people in organisations differ (Day, 1995)

Numerous authors have reported on the effects that a diverse workforce has on both the functional and human aspects of organisations. On the one hand, various studies have confirmed

Requests for copies should be addressed to: L.J. van Vuuren, Programme in Industrial Psychology, Department of Human Resource Management, RAU, PO Box 524, Auckland Park, 2006 the negative consequences of diversity. Van Eron (1995) states that diversity in itself does not automatically lead to a competitive edge and that it is more likely to result in tension, conflict, misunderstanding and frustration if not adequately managed. Milliken and Martins (1996) have found that the greater the diversity in an organisation, the higher the dissatisfaction and turnover. Furthermore, diversity that is not effectively managed has major cost implications for organisations in terms of employee absenteeism, poor performance as a result of unresolved intergroup dynamics, harassment behaviour, discrimination suits, and inefficient communication (Cox, 1997).

On the other hand, a number of studies have indicated that, when managed correctly, diversity can greatly benefit the organisation. For example, Gordon (1995) has found that diversity can result in a competitive edge, and may positively impact on financial performance. Furthermore, a diverse workforce results in a larger pool of knowledge, skills and abilities, and is essential for creativity and innovation (Hayles \& Russell, 1997). Diversity is also vital in the targeting and servicing of new markets, as the organisation's perspective is broadened and employees are sensitised to enable them to interact with all market groups. Intercultural co-operation is facilitated by means of diversity, and results in the design of structures, systems and organisational initiatives that promote global functionality (Hayles \& Russell, 1997). Van Eron (1995) supports the argument that if properly managed, diversity can benefit the organisation, as it will ensure that the best talent in the labour pool is attracted and retained. In addition, employee satisfaction, morale and commitment to these organisations have been found to increase, resulting in the elimination or reduction of lawsuits and penalties related to discrimination.

In summary, organisations depend on the talents of their workforce to succeed, and talent is distributed across all groups of people, regardless of their differences. Thus, irrespective of 
whether diversity is beneficial or detrimental to organisations, it is an ever-growing reality that is here to stay (Greenhaus \& Callanan, 1994). To capitalise on this phenomenon, organisations must be able to embrace, value and effectively manage diversity (Human, 1996). Managing diversity entails a comprehensive managerial process of actively developing an environment that benefits all employees (Hermon, 1996). This includes valuing diversity, which means that all people regardless of their differences, must be seen as having equal rights (Schreiber, 1996). Only organisations that value the unique contributions of all individuals, and accept that employee's differences compete with as well as complement each other, will achieve a competitive advantage (Lubinski \& Dawis, 1994). In this way, the effective management of diversity entails the improvement of organisational performance by maximally making use of every employee's ability, and by using diversity as an organisational resource (Cox \& Beale, 1997).

The general trend in South African organisations with regard to managing diversity seems to be a movement towards diversity training. Laird (1985) defines training as an experience, discipline or regimen that causes people to acquire new, predetermined behaviours. It can thus be said that the objective of diversity training initiatives is to modify the behaviour of people (Thomas, 1994) to eliminate discrimination. Diversity awareness training is a popular type of diversity training initiative. It is often met with confusion, disorder, approval, reverence, bewilderment and even hostility. Subjective bias is commonly linked to diversity awareness training (Thomas, 1994), and will greatly affect outcomes and the degree to which behaviour is changed. It is also important to note that behaviour is affected and influenced by various other personal dimensions, including physiological responses, affective reactions, interpersonal interaction and cognition (Patterson, 1986). Diversity awareness training therefore aims at affecting the cognition of individuals, which in turn will result in a change of behaviour.

A minority of South African organisations still resist diversity initiatives, fearing that they are expensive, have a negative effect on productivity, and disrupt the workplace (Mathews, 1998). Most organisations are dispelling the belief that diversity training is nice-to-have yet not essential to business, and are beginning to acknowledge and accept its importance (Diamante et al., 1995). These organisations have diversity strategies and make use of training programmes (that incorporate individual differences) to make employees more aware of diversity and its implications, as well as to contribute towards the organisational culture in a positive way (Diamante et al., 1995).

\section{Theoretical background}

Various existing theoretical models can be used to explain the impact that diversity has in the workplace, as well as the need for and importance of diversity awareness training in addressing diversity issues. A selection of these models are presented below.

An adaptation of Hopkins' Process Model of the Ethics-Diversity Relationship (Hopkins, 1997) can be used to explain the way in which diversity impacts on the functioning of the organisation (see Figure 1). The cultural network of the organisation is a mechanism that stabilises the corporate culture of an organisation. It is responsible for social information processing related to values, beliefs, attitudes and behaviours in the organisation. In today's diverse workforce, English is not the first language of all employees. This affects the extent to which verbal, non-verbal and written messages sent through the cultural network are understood. The functioning of the cultural network affects the stability of the corporate culture, which in turn will impact on the ethics paradigm. The organisation's ethics paradigm defines formal and informal moral standards that dictate acceptable behaviour of people in striving towards organisational goals that are in line with the organisational values (Hopkins, 1997). Since research has shown that the corporate culture influences the ethical standards and moral practices of individuals (Hopkins, 1997), it can be said that the ethics paradigm in turn will regulate the functioning of the entire organisation, affecting aspects such as performance management, career development, teamwork, work-family issues, participation, and relationships.

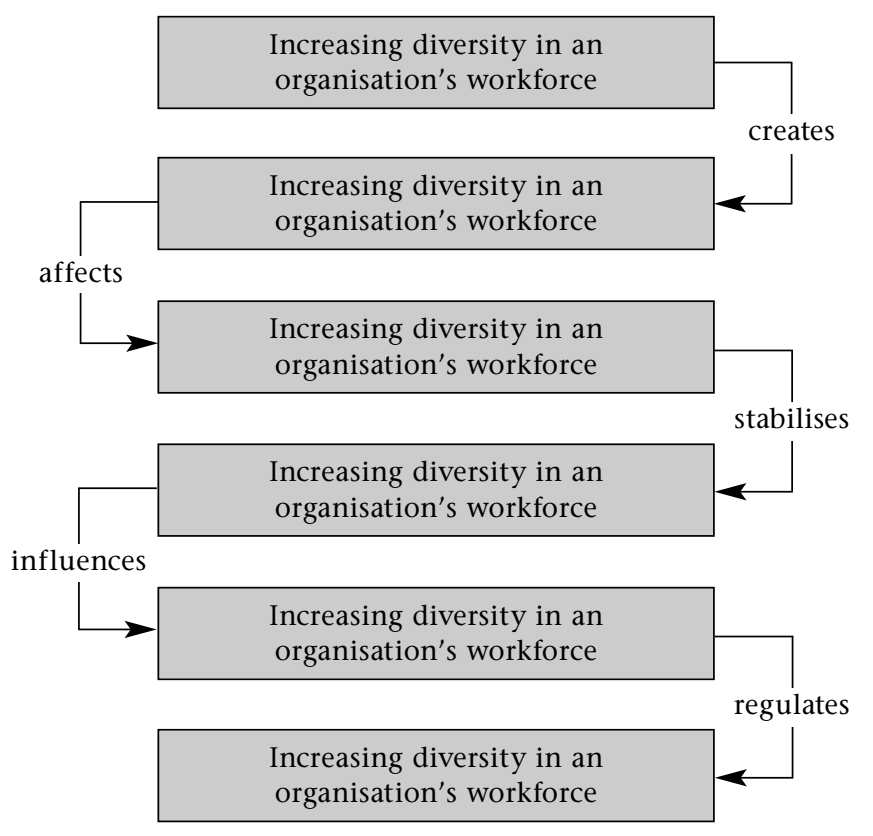

Figure 1: An adaptation of Hopkins' process model of Ethics - diversity relationships (Hopkins, 1997, p.16)

The adaptation of Hopkins' Process Model of Ethics-Diversity Relationships is based on cognitive theory. Cognitive psychology focuses on "higher" mental processes such as memory, reasoning, information processing, language, problemsolving, decision-making and creativity (Weiten, 1983). Behavioural therapists increasingly recognise the need to address people's cognitive processes (such as thoughts, attitudes, beliefs, attributions and expectations) directly. The underlying premise of the cognitive theory is that the way people view and interpret events in the environment will influence the way they behave. That is, the meaning people place on events, people and things; and the beliefs and expectations they have of these, will determine behaviour (Spiegler, 1983). It is thus logical that diversity awareness training is based on this theory, aiming to change people's behaviour by first influencing their thoughts, attitudes, beliefs, attributions and expectations.

There are numerous other models documented that are based on cognitive theory that have been developed to facilitate diversity initiatives on individual, group and organisational levels. This study focuses on individual and group development models. It is based on the view of Hayles and Russell (1997) that organisational change and development with respect to diversity is greatly facilitated if individuals have already been progressing through stages of development under conditions that reduce bias and enhance acceptance and respect.

\section{Individual development models}

Bennett's Model of Developing Intercultural Sensitivity consists of six stages: denial of difference, defense against difference, minimisation of difference, acceptance of difference, adaptation to difference, and integration of difference. While this model was designed for intercultural issues, it is applicable to broader diversity issues (Hayles \& Russell, 1997). The Mendez-Russell Model is applicable to a broad range of differences. According to this model, individual development is dependent on four phases: knowledge, understanding, acceptance and behaviour (Hayles \& 
Russell, 1997). Steve Hanamura distinguishes eight stages of individual development regarding diversity: discovery, anger, withdrawal and self-doubt, seclusion, rebirth, the need to belong, the con artist, and self-actualisation (Hayles \& Russell, 1997). Terry L. Cross describes development in six stages: destructiveness, incapacity, blindness, pre-competence, basic competence, and proficiency (Hayles \& Russell, 1997).

\section{Group development models}

Two basic strategies for group development are highlighted by Hayles and Russell (1997), namely to assess the distribution of individuals in the organisation and develop initiatives that will incorporate the majority of these people; and to conduct a thorough needs analysis, identifying specific issues, and determining goals with regards to each group of individuals. The Contact Hypothesis is the model most commonly used to reduce prejudice in a group context. The strategy used is to reduce prejudice by creating ideal contacts among individuals within the group. According to this model, ideal contact conditions for reducing prejudice include: equal status within the group; the group has or experiences a positive perception of another group; other majority group members are involved; the group is or will take part in an activity requiring intergroup cooperation; the situation involves interdependence; contact is more intimate than casual; authority and/or the social climate promote intergroup contact; and contact is pleasant and rewarding.

In their support of the individual and group development models discussed above, Hayles and Russell (1997) state that change relating to diversity begins with cognitive change, as learning about and understanding people who are different takes place (cognitive). The process then continues when one's behaviour is modified (conative), and one's behaviour shows understanding and acceptance of those who are different. And finally, change relating to diversity involves emotional growth (affective). It is at this stage that authentic relationships can develop with people who are different. If this progression is hindered in any way, further development will not occur, and regression to an earlier stage is likely (Hayles \& Russell, 1997).

Cox and Beale (1997) refer to "diversity competence", which is a process of learning that enables individuals to effectively respond to the challenges and opportunities that arise in a diverse system. This learning process involves three stages: awareness (recognising that diversity has a very real effect on organisational behaviour and outcomes); knowledge and understanding (where a deeper understanding is achieved of why diversity competence is relevant to the performance of individuals, groups and organisations); and behaviour and action steps (where behaviour is changed). This process of learning should be applied in areas such as performance management, employee development, conflict resolution, group decision-making, selection and delegation, and empowerment.

The theory discussed above supports Human's (1996) belief that to address the diversity issue in organisations, awareness of diversity should be the first stage of the process to enable individuals to manage their own prejudices and stereotypes. It can be concluded that diversity awareness training aims to achieve this personal awareness (on a cognitive level), and is thus the preferred initiative in addressing diversity issues. It is against this theoretical backdrop that this research has been conducted.

\section{Organisational dimensions of diversity}

The urgent need to implement diversity initiatives in South Africa is evident. Human (1996) recommends that diversity training programmes should focus on giving people the skills to understand diversity in a different way, thereby diffusing stereotypes and value judgements which will enhance the quality of social interaction. However, organisations should not lose sight of the fact that the success of any initiative greatly depends on the measurement thereof. Rynes and Rosen (1994) identify two reasons why measurement is vital: firstly, to assess cost and secondly, to identify the success of the initiative (outcomes may be positive, neutral or negative).

A study of relevant literature has indicated that when measuring the success of diversity awareness initiatives, a number of organisational dimensions should be considered and assessed to determine the effect of the initiative. Work climate is one such organisational dimension. It includes perceived fairness, stereotyping, intergroup conflict and intergroup differences in employment satisfaction (Cox, 1997); and cultural environment (Mathews, 1998). A second organisational dimension is career experience, which includes job mobility and promotion measures (Cox, 1997); management and evaluation measures (Mathews, 1998); and performance management, succession planning, development assessment measures and training opportunities (Diamante et al., 1995). Cox (1997) identifies a third organisational dimension - first level organisational outcomes. These include employee absenteeism and turnover, innovation, productivity, customer satisfaction (Cox, 1997). A final organisational dimension that should be considered is second level organisational outcomes, which addresses the results of market share, profits, and the accomplishment of the organisational mission (Cox, 1997).

In addition to the above, Norton and Fox (1997) stress the importance of assessing diversity on four functional levels: culture (mission, goals, and underlying assumptions); structure (systems, policies, and practices); roles and responsibilities (of individuals or team members); and work relationship skills (at the interpersonal level as well as between the individual and organisation).

Based on the evidence above, 11 organisational dimensions have been identified that should be measured to assess the effectiveness of diversity awareness training. These dimensions include: awareness of self, impact of differences, performance management, career development, teamwork, work-family needs, participation, company culture, relationship building, general satisfaction with the organisation and job satisfaction. A brief overview of these organisational dimensions and their relation to diversity follows.

\section{Dimension}

1. Awareness of self

The first step in addressing diversity is an analysis of the self. Individuals need to be aware of personal patterns (personal attitudes and opinions), and have an understanding of interpersonal and cultural patterns. It is this self-knowledge that allows people to be non-judgmental and open.

Research has shown that levels of confidence also affect actions. People with high levels of confidence tend to attribute their success to their own skills and abilities. Failure will motivate these individuals to work harder. It has been found that only people who are willing to accept their own strengths and weaknesses and who look critically at their own interaction with other cultures will be able to master effective interaction with others.

\section{Impact of differences}

The magnitude of differences in the workplace has been associated with reduced levels of organisational attachment and social integration. Types of differences in the workplace include:

Barry \& Bateman (1996); Chatman, Polzer \& Neale

\section{Further reading}

Griggs \& Louw (1995);

Hayles \& Russell (1997);

Human (1996); Koonce

(1997); Schreiber (1996) 
- Physical characteristics: the more visible the differences between people (e.g. physical features such as race and gender) the more likely they are to evoke responses directly linked to biases, prejudices and stereotypes

- Personal appearance: includes hygiene, grooming, eating habits and dress. While there are business reasons for mandating appearance, looks-based judgments are discriminatory and have legal implications

- Language: the grammatical facts and categories people speak will influence and determine the way they think

- Background: the more similar people are in background, the more attracted they are to each other

Two psychological theories can be used to assess the impact of differences in the workplace:

- The reinforcement-affect model of attraction: people tend to like people who are similar to themselves and dislike those who are dissimilar.

- The social comparison theory: people compare their abilities and opinions with the abilities and opinions if those who are similar to them.

Based on these theories it has been found that similarity is the basis of social interaction. People trust and interact more with those who are similar to themselves. The more individuals share a sense of belonging and identification in terms of common interests, values, goals and difficulties, the more comfortable and accepted they feel; and the greater their levels of self-confidence, motivation and productivity.

In a supportive environment, differences can become assets, providing opportunities for innovation and competitive advantage. The difficulty in organisations is being able to measure people's awareness of differences to achieve a level of understanding.

\section{Performance Management}

Organisations depend on the talent of their workforce to succeed, thus human resource development is essential for organisations to remain competitive and plan for the future. Performance management assists employees (especially from designated groups) with their development. For performance management to be successful in a diverse workforce, all employees must be treated as unique individual with different strengths, weaknesses, problems and training needs. Continual feedback is also essential. Performance management may be a problem area, especially where a manager has to evaluate someone who is different to him/her. If there is any degree of racism or sexism in the performance management process, resistance towards diversity-related initiatives is likely.

\section{Career Development}

Every individual in an organisation has the right to become actively involved in an ongoing learning process to develop himself/herself on a professional and personal level. The greater the competency level of each individual, the more significant and effective the contribution made by each towards the attainment of organisational goals. One of the biggest dilemmas in South Africa at present is the need to advance previously disadvantaged groups without violating the rights of other groups (specifically the white male). In today's diverse workforce, negative perceptions of management towards disadvantaged groups, coupled with the lack of people management skills and accountability, is a primary reason for the failure of the advancements of certain groups. Certain Black advancement programmes that have been introduced either re-enforce stereotypes concerning Black underperformance, or result in a self-fulfilling prophecy for these groups.

A solution to this dilemma is mentorship, which is essential for career success and for upward mobility for all groups of employees.

\section{Teamwork}

Research has shown that organisations that encourage teamwork are more likely to succeed with regards to diversity. It is within the team environment that diversity issues are recognized and addressed, as creating a team identity facilitates the establishment of operating norms. Teamwork also creates bonds with employees, and plays an important part in defining the role of the individual and others in the workplace.

Successful teams allow individuals to feel that their contributions are valued, enhancing innovation, communication and satisfaction. However, diverse teams that have not learned to manage their differences will perform at a lover level than homogeneous groups.

Self-directed work teams provide advanced empowerment by enhancing shared responsibility and flexible tasks. They are managed through information sharing and participative decision-making, and are considered to be one of the most natural means for incorporating and promoting diversity in twenty-first century organisations.

\section{Work-family needs}

Managers are faced with the challenge of managing employees with difference lifestyles. The needs of single parents, unmarrieds with spousal roles, gay couples, job sharers, dual income families or physically challenged people need to be accommodated and met. For example, employees who try to maintain a balance between work and family responsibilities may be seen as being less committed. Travel and long hours result in parents of dual income families spending more time away from home. Childless employees may feel their own needs and concerns are overlooked: that they are unfairly expected to carry the workload, do more of the traveling, work later hours, and subsidise the benefits of employees with children. Low wage employees often experience more challenges than those who can afford a wider range of facilities and services.

Ege (1999); Hopkins (1997); Human (1996)

Davis \& Rodela (1997); Hayes \& Hollman (1996); Tsukudu (1996); Schor (1997)

Hayles \& Russell (1997) Mendzela (1997); Schreiber (1996); Smith \& Berg (1997)

Cox (1997); Rodwell, Kienzie \& Shadur (1998); Settle-Murphy (1996); Slobodnik \& Slobodnik (1996)

Editor (1997); Hickman \& Creighton-Zoller (1998)

Mathews (1998); Morris (1997); Norton \& Fox (1997); Parkinson (1997); Rosen \& Lovelace (1994) 
Flex-management is a tool that can be used to balance work and family needs. It includes flexibility in working hours and rewards (like reduced hours, part-time work, and compressed workweeks).

\section{Participation}

Employees who believe that their contributions are not valued will not be motivated to contribute. In order to succeed, organisations need to find ways of maximizing the contributions of its intellectual capital. An inclusive environment should be created in which each individual feels valued, welcome, and able to make a meaningful contribution in the accomplishment of organisational goals. Research has shown that sharing information about the organisation, its activities, goals and directions \& is the most effective way of fostering employee participation. Linked to this is communication. Lack of communication is one of the biggest barriers to effective diversity management. By means of communication, employees receive the information they need to be able to contribute to their maximum potential.

\section{Company Culture}

Each member of today's diverse workforce has his/her own idea of what constitutes morally right and wrong behaviour. It is thus the task of management to communicate a common organisational culture effectively to ach employee, and to communicate their commitment to a culture that supports fair and equitable practices.

Acculturation refers to the process of addressing cultural differences and to cultural change and adaptation between groups. In a modern multinational organisation, integration is the preferred acculturation mode, where both culture groups change to a certain degree to reflect a common set of norms and values.

\section{Relationship building}

Relationships provide a source of social support, which assists in the reduction of stress and staff turnover. Socialisation within the organisation is also dependent on relationships, and information obtained from peers assists in the learning of tasks and social information. People need relationships to make sense of the organisational environment, as well as their self-identity and self-image. Strong formal relationships are predictive of an individual's access to promotions, and ensure access to information needed to perform.

Organisationally sponsored events play an important role in the development of relationships. Groups excluded from social activities leads to their isolation, resulting in decreased commitment and increased turnover.

\section{General satisfaction with the organisation}

If managed effectively, diversity can lead to greater employee satisfaction, morale and commitment to the organisation. Research has shown that employees who are satisfied with and committed to the organisation are more likely to participate in organisational activities and perform at levels necessary to achieve organisational goals.

\section{Job satisfaction}

It has been found that employees are satisfied with their jobs when workplace priorities are in agreement with their own personal values, when passion and purpose are present in their jobs, and when the job they have chosen presents growth opportunities.

Martinez (1997); Mathews (1998)

Chatman, Polzer \& Neale (1998); Egge (1999); Hermon (1996); Miller (1998); Rodwell, Kienzie Shadur (1998)

Barry \& Bateman (1996); Hayles \& Russell (1997); Milliken \& Martins (1996)

Barry \& Bateman (1997); Beekie (1997); Cox \& Finley-Nickelson (1997); Hopkins (1997); Norton \& Fox (1997); Paskoff (1996); Van Buren (1997)

Clarke (1994); Editor a (1995); Fritz (1997); Norton \& Fox (1997)

Rosen \& Lovelace (1994)

Milliken \& Martins (1996); Van Eron (1995); Hopkins (1997); Whitehead (1998)

Baron (1998); Brown (1998); Cox \& Nkomo (1996); Tietjien \& Myers (1998)
The question of how to manage these 11 organisational dimensions to ensure that organisations benefit from diversity should be considered. There are numerous approaches that can be used to address the issue of diversity in the workplace. Some of these include team building, management initiatives, selfdirected work teams, reengineering (Norton \& Fox, 1997), work design, staffing, compensation, and training and development (Barry \& Bateman, 1996). According to Schreiber (1996), training is a natural step for organisations to address diversity in that it encourages participation of individuals through the team management theory. The American approach appears to be the preferred option in South Africa - that is, diversity programmes implemented are a substitute for a more direct approach to address racism and sexism. These interventions are focused on increasing the number of blacks in managerial positions, and do not challenge the problematic paradigms held by management regarding the role of training and development (Human, 1996).

Many organisations are benefiting from diversity training, but reports of positive results are not as common as the negative feedback documented (Day, 1995; Foty, 1995; Rynes \& Rosen, 1994). Whereas South African companies claim to be addressing the diversity issue, Gordon (1995) has found that many of the initiatives implemented are merely "affirmative action in drag". Human (1996) and Paskoff (1996) agree that diversity initiatives are largely ineffective, wasting valuable time and often magnifying the problems they are meant to address. Drawing attention to differences in this way has a major potential legal risk for organisations (Paskoff, 1996). The majority of white male managers express their commitment to employment equity, and the programmes that have been implemented to facilitate the process, but many blacks and women have expressed anger and frustration, claiming that nothing has actually changed. Cox (1997) has documented participants of diversity training programmes claiming that they are merely made more aware of differences in this way, and are forced to think of people in categories. Norton and Fox (1997) agree that this leads to the goals of the various identity groups separating further from the goals of the organisation. Carnevale and Kogod (1996) add that some of these diversity programmes fail because they are out of context and do not address real experiences of employees. Other diversity programmes focus on past injustices, to see which group has suffered the most. And still other programmes aim at sensitising one group (mainly white male managers), while assuming that other groups do not need assistance. Mathews (1998) concludes by stating that these quick fix, inappropriate initiatives lead to loss of motivation and low productivity, and are extremely costly to organisations.

From the findings discussed above, it appears as though organisations are unclear as to whether they are striving towards affirmative action, employment equity or the management of 
diversity. The goals of training initiatives are thus not clearly defined. According to Cox and Beale (1997), employment equity is a goal determined by legislation. Affirmative action is a tool used to achieve employment equity. And managing diversity is a process driven by business trends as well as the quest for organisations to maximise economic performance and fulfill the mission of the organisation. Furthermore, it can be concluded that most workshops and programmes that have been created serve merely to reinforce the differences between "us" and "them", and do not challenge the real problems associated with the management of a diverse workforce. While this trend is not unique to South Africa, the relevance of cultural differences in interpersonal interaction does not receive adequate attention (Human, 1996).

For a diverse workforce to add value to any organisation, employees need to develop from a negative or neutral perspective of differences to a positive perspective where differences are accepted, respected and valued (Hayles \& Russell, 1997). Based on the theory discussed in this study, it has been concluded that organisations should initially address what employees know and understand about diversity. Once this has been achieved, how employees feel and act should then be managed.

Numerous South African organisations are initiating diversity awareness training in an attempt to address the common problems associated with a diverse workforce. Not only are employers beginning to understand the business case for the management of diversity, but current legislation has also been implemented to ensure discrimination free workplaces. This study aims to assess whether diversity awareness training is effective in addressing the diversity issue in the workplace. The question to be asked is whether such initiatives are actually bringing about constructive change, or are merely being used as window-dressing to avoid legal and other consequences. Based on the theory discussed in this article, diversity awareness training should, as a long-term initiative, initiate change on a cognitive level first, then on a conative and finally on an affective level. For the purpose of this study, the impact of a specific diversity awareness training programme initiated at an international accounting firm will be assessed. As part of the assessment, it will be determined which of the 11 organisational dimensions identified in this study are positively and significantly affected through the use of the diversity awareness training programme.

\section{METHOD}

\section{Participants}

A sample of 382 of the 1137 employees at an international accounting firm was selected by the human resource director to take part in the study. These employees were from 4 of the 22 departments in the organisation, and were selected based on two criteria:

- Results of an internal climate survey previously conducted. These four departments scored similarly in each of the following categories of the climate survey: client orientation; appraisal and recognition; communication; cooperation and teamwork; efficiency and innovation; job satisfaction; loyalty and commitment; management and strategy; market orientation; reward; supervision; synergy; training, development and career; and work organisation.

- The four departments were similar in terms of the functions they fulfill within the organisation.

The sample was representative in terms of age, population group, gender and level in the organisation. The composition of the sample is presented in Table 1. For the purpose of this study and to ensure confidentiality of results, "Whites" will refer to white participants, and "Blacks" will refer to Black, Indian and coloured participants.
TABLE 1

Crossbreak of population group AND JOB LeVel

\begin{tabular}{lcccccc}
\hline & $\begin{array}{c}\text { Partners/ } \\
\text { Principals }\end{array}$ & $\begin{array}{c}\text { Senior } \\
\text { managers }\end{array}$ & Managers & Supervisors & Trainees $\begin{array}{c}\text { Administrative } \\
\text { staff }\end{array}$ \\
\hline Black males & 1 & 1 & 0 & 1 & 34 & 0 \\
White males & 24 & 13 & 17 & 12 & 105 & 0 \\
Black females & 0 & 0 & 3 & 1 & 35 & 2 \\
White females & 1 & 6 & 24 & 10 & 68 & 24 \\
\hline
\end{tabular}

\section{Measuring instruments}

Two questionnaires were used in the study. The first was designed (based on the literature study) to measure 10 of the 11 organisational dimensions identified in this study: awareness of self, impact of differences, performance management, career development, teamwork, work-family needs, participation, organisational culture, relationship building, and general satisfaction with the organisation. The questionnaire consisted of 68 statements, with accompanying 7-point Likert scales. Participants were requested to read each statement and respond in terms of the extent to which they agreed/disagreed with each statement $(1=$ strongly disagree and 7 = strongly agree $)$.

The questionnaire used to measure the 11th organisational dimension (job satisfaction) was the short version of the Minnesota Job Satisfaction Questionnaire (MSQ) developed by Weiss, Dawis, England and Lofquist (Welman \& Basson, 1995). The MSQ is a rating scale designed to measure job satisfaction, specifically in terms of implementation of ability, achievement, activity, advancement, authority, organisational policies and practices, compensation, co-workers, creativity, independence, moral values, recognition, responsibility, security, social service, social status, supervision (human relations and technical), variety, and working conditions. The short version of the MSQ consists of 20 questions that measure the extent to which employees are satisfied with various aspects of their current job (Welman \& Basson, 1995).

\section{Experimental design}

Three possible one-treatment condition experimental designs were considered to measure the effect of the treatment: the preand posttest control group design, the posttest-only control group design, and the Solomon four-group design. The latter was implemented for this study as it is the most powerful approach (Leedy, 1993). This design is underused for a number of reasons. Braver and Braver (1988) explain that firstly, there is a perception that twice the number of participants is required to implement this design. Whereas the number of groups required is indeed double that of other designs, the number of participants does not necessarily have to be greater. Secondly, some researchers are not interested in measuring pretest sensitisation effects. Thirdly, researchers avoid the Solomon four-group design as it is viewed as being more complicated than other designs, in the sense that it allows for numerous comparisons. Lastly, there appears to be a lack of certainty surrounding the most appropriate statistical treatment of the design. Kerlinger and Lee (2000) confirm that one of the biggest concerns with the Solomon four-group design is how to identify the overall statistical approach that will take into consideration data from all four groups.

Although the concerns linked to the use of the Solomon fourgroup design were considered, the design was selected for this study, because it assesses the effect of the treatment (that is, the diversity awareness training programme) while minimising threats to internal validity. For example, Kerlinger and Lee (2000) state that this design offers strong control of most extraneous variables such as the control of history and maturation, which would otherwise affect results obtained. Furthermore, it is the most effective method to assess the 
presence of pretest sensitisation and its effect on the dependent variable. Sensitisation means that participants exposed to the pretest will be more sensitive to the experimental treatment, thereby preventing the generalisation of results from the pretested sample to a non-pretested group. Consequently, the Solomon four-group design affords a higher degree of both internal and external validity compared to other research designs (Braver \& Braver, 1988). And finally, this design allows for multiple comparisons (Kerlinger \& Lee, 2000).

A number of authors have suggested possible statistical treatments for the Solomon four-group design: Leedy (1993) and Huysamen (1994) suggest a two-factor analysis of variance, whereby the posttest scores will be assessed in terms of the significance of the treatment, the significance of the pretest, and the significance of the interaction between the treatment and the pretest (groups $\mathrm{O} 2, \mathrm{O} 4, \mathrm{O} 5$ and $\mathrm{O} 6$ in Table 2). If an analysis of variance yields significant results, the question is whether the pretesting enhances or reduces the effect of the treatment. This can be answered by means of a "subtractive difference" procedure, which involves studying the differences between the performance outcomes in the four groups (Rosenthal \& Rosnow, 1991, p.87). Kerlinger and Lee (2000) further recommend conducting an analysis of covariance. In this way, the posttested scores of the experimental group can be tested against each other using a t test or an F test (groups $\mathrm{O} 2$ and $\mathrm{O} 4$ in Table 2). Groups $\mathrm{O} 5$ and $\mathrm{O} 6$ can also be tested against the average of $\mathrm{O} 1$ and $\mathrm{O} 2$, and the significance of the difference of $\mathrm{O} 2$ and $\mathrm{O} 4$ can be tested (see Table 2).

There are two problems with the recommendations above that need to be considered. The first is the unreliability of the difference scores. To produce significant results, the effect has to be strong, and the scores assessed must be reliable enough to indicate statistically significant results (Kerlinger \& Lee, 2000). The second problem involves integrating the recommended statistical approaches into one overall statistically powerful approach. This concern has been addressed through the use of the statistical approach provided by Braver and Braver (1988). Their recommendation is in agreement with the work of Campbell and Stanley (1963) and Huck and Sandler (1973), as well as the other authors mentioned above, but covers more contingencies and has more statistical power (ability to detect significance). It is a unique approach in that it uses the results from all four groups of the Solomon four-group design. Maximum power is thus achieved as a test is included in the approach that combines the test of the treatment in Groups 1 and 2 (the pretested groups) with the test of the treatment in Groups 3 and 4 (the posttest only groups) (see Table 2). The Solomon four-group design is presented in Table 2.

TABLE 2

\section{THE SOLOMON FOUR-GROUP EXPERIMENTAL DESIGN}

\begin{tabular}{ccccc}
\hline Group & & Pre-test & Treatment & Post-test \\
\hline 1 & $\mathrm{R}$ & $\mathrm{O} 1$ & $\mathrm{X}$ & $\mathrm{O} 2$ \\
2 & $\mathrm{R}$ & $\mathrm{O} 3$ & & $\mathrm{O} 4$ \\
3 & $\mathrm{R}$ & & $\mathrm{X}$ & $\mathrm{O}$ \\
4 & $\mathrm{R}$ & & & $\mathrm{O} 6$ \\
\hline
\end{tabular}

Where $\mathrm{O}=$ outcome measure; $\mathrm{X}=$ treatment; $\mathrm{R}=$ randomisation

\section{Procedure}

The four departments in the sample (pre-selected by the human resource director based on the criteria discussed previously), were divided further by the human resource director to form two groups, namely the experimental group (two departments), and the control group (two departments). The participants in each group were then randomly divided into two groups each to form four separate groups (Groups 1, 2, 3 and 4). Groups 1 and
3 were experimental groups and Groups 2 and 4 were control groups. Groups 1 and 2 were given a pretest to complete. Groups 1 and 3 attended a diversity workshop in business unit-based groups of 20 people. A representative sample in terms of seniority, population group and gender was achieved in each group. A month after Groups 1 and 3 attended the training workshop, Groups 1, 3 and 4 were posttested. Group 2 was posttested a month after completing the pretest.

The questionnaires completed by individuals during pretesting were matched with their respective questionnaires completed during posttesting. Due to the fact that confidentiality of results was essential, not all questionnaires could be matched successfully. The questionnaires of participants who voluntarily filled in their names were matched with ease. Anonymous questionnaires were matched by means of a process of elimination (where possible), by referring to and comparing the biographical data provided. To facilitate this process, posttests distributed to individuals in the experimental group who had completed a pretest, were marked with a red dot to make them easily identifiable. Of the 387 people who took part in this study, only five pairs of questionnaires could either not be matched or not all the items were completed.

The type of training implemented was diversity awareness training. According to Innes, Kentridge and Perdd (1993), diversity awareness training is aimed at increasing employees' awareness of the meaning and importance of valuing diversity. It is not meant to teach specific skills, but rather to sensitise employees to the assumptions they make of others, and how these assumptions influence their behaviour, decisions and judgment. External consultants designed and presented a two-day diversity awareness workshop at the accounting firm. This workshop dealt with racism, sexism, classism, bias, prejudice and discrimination, and was designed to help individuals understand their own conditioning and make decisions about their beliefs and behaviour. The rationale is that once individuals have understood where their thoughts come from, they are forced to own their beliefs, attitudes and actions rather than blame history for these. While the workshop focused on the individuals present, as well as their distinctive sets of needs and issues, each session (while unique) was linked in terms of content.

During the workshop, the facilitators probed for clarity, understanding and honesty. Exercises used were based on gender and population group perceptions to provide participants with insight into their stereotyping and programming. Cultural influences were then explored, using a model that outlines the environment that each participant is born into (class, ethnicity, childhood geography, language, gender, population group, family values, age, ability), and the impact that this has on adult choices they have made (such as profession, beliefs, education, sexual orientation, marital status, behavioural styles, adulthood geography, personal values). Participants also watched the film "A class divided" with the aim of sensitising them to the situation and feelings of those who are discriminated against. The Employment Equity Act and its ramifications to South African organisations were discussed in groups where this was a perceived need. The remainder of the workshop was designed to create change through the application of various models intended to change beliefs and attitudes. Participation and feedback was obtained throughout, and participants were asked to create their own personal projects based on what they had learned in the workshop. The workshop was not intended to be a once-off intervention. Follow-up sessions are also being planned for the departments concerned.

\section{RESULTS}

Due to the fact that the organisational dimensions of the questionnaire used were logical dimensions (i.e. items were logically and not statistically categorised into factors), it was necessary to test the internal consistency of the dimensions. The 
questionnaire designed for the purpose of this study was overall highly reliable (Cronbach alpha equal to 0,93 ). The reliability of the Minnesota Job Satisfaction Questionnaire was also high (Cronbach alpha equal to 0,91 ). Some of the internal consistency reliabilities of the ten logical dimensions were not acceptable, and therefore a principal axis factor analysis followed by direct oblimin rotation was conducted using the score totals on the ten organisational dimensions as input. One factor (Scale 1) which explained $54 \%$ of the variance, was extracted (as indicated in Table 3). Scale 1 made logical sense, and was renamed awareness of diversity. The Minnesota Job Satisfaction Questionnaire was regarded as a second factor (Scale 2). These two scales were then used in subsequent analyses, as both were highly reliable.

TABLE 3

FACTOR PATTERN MATRIX OF THE TEN ORGANISATIONAL DIMENSIONS

\begin{tabular}{lc}
\hline Organisational Dimension & Factor 1 \\
\hline Company culture & 0,89 \\
Teamwork & 0,84 \\
Participation & 0,78 \\
Career development & 0,77 \\
General satisfaction with the organisation & 0,77 \\
Relationship building & 0,77 \\
Performance management & 0,68 \\
Work-family needs & 0,55 \\
Awareness of self & 0,50 \\
Impact of differences & 0,32 \\
\hline
\end{tabular}

The statistical treatment recommended by Braver and Braver (1988) was used to analyse and interpret the results of this study. A flowchart summarising statistical tests conducted and conclusions obtained, is provided in Figure 2. The path followed for this study has been shaded.

Descriptive statistics for the Solomon four-group design that were analysed, are represented in Table 4 . What follows is an explanation of Figure 2 making use of the descriptive statistics in Table 4.
TABLE 4

DESCRIPTIVE STATISTICS FOR THE VARIOUS GROUPS OF THE SOLOMON Design, $\mathbf{N}=382$

\begin{tabular}{|c|c|c|c|c|c|c|c|c|}
\hline \multirow[b]{2}{*}{ Group } & \multicolumn{2}{|c|}{ Pretest } & \multicolumn{2}{|c|}{$\begin{array}{l}\text { Correlation } \\
\text { between pre- } \\
\text { and posttest }\end{array}$} & \multicolumn{2}{|c|}{ Posttest } & \multicolumn{2}{|c|}{$\begin{array}{c}\text { Correlation } \\
\text { between Scales } \\
1 \text { and } 2\end{array}$} \\
\hline & $M$ & $S D$ & $r$ & $p$ & $M$ & $S D$ & $r$ & $p$ \\
\hline \multicolumn{9}{|l|}{1} \\
\hline Scale 1 & 320,27 & 46,21 & 0,61 & 0,00 & 323,50 & 45,71 & & \\
\hline Scale 2 & 107,53 & 16,89 & 0,60 & 0,00 & 105,86 & 15,89 & & \\
\hline \multicolumn{9}{|l|}{2} \\
\hline Scale 1 & 320,49 & 40,79 & 0,88 & 0,00 & 319,51 & 37,34 & & \\
\hline Scale 2 & 104,96 & 14,99 & 0,66 & 0,00 & 103,66 & 13,81 & & \\
\hline \multicolumn{9}{|l|}{3} \\
\hline Scale 1 & & & & & 322,22 & 39,95 & 0,70 & 0,00 \\
\hline Scale 2 & & & & & 106,63 & 15,45 & 0,70 & 0,00 \\
\hline \multicolumn{9}{|l|}{4} \\
\hline Scale 1 & & & & & 327,57 & 38,13 & 0,74 & 0,00 \\
\hline Scale 2 & & & & & 102,65 & 19,57 & 0,74 & 0,00 \\
\hline
\end{tabular}

Test $A$ was carried out to determine the presence or absence of pretest sensitisation. For pretest sensitisation to be present, it would be expected that the groups that received the pretest would have more positive results than the groups that did not receive the pretest. Test A involved a 2 X 2 between-groups analysis of variance (ANOVA) on the four posttest scores, presented in Table 5 .

TABLE 5

2 X 2 BETWEEN-GROUP ANOVA OF THE FOUR POSTTEST GROUPS' SCORES

\begin{tabular}{lll}
\hline Pretest & \multicolumn{2}{c}{ Treatment (X) } \\
\cline { 2 - 3 } & Yes & No \\
\hline Yes & $\mathrm{O} 2$ & $\mathrm{O} 4$ \\
No & $\mathrm{O}$ & $\mathrm{O}$ \\
\hline $\mathrm{O}=$ outcome measure & &
\end{tabular}

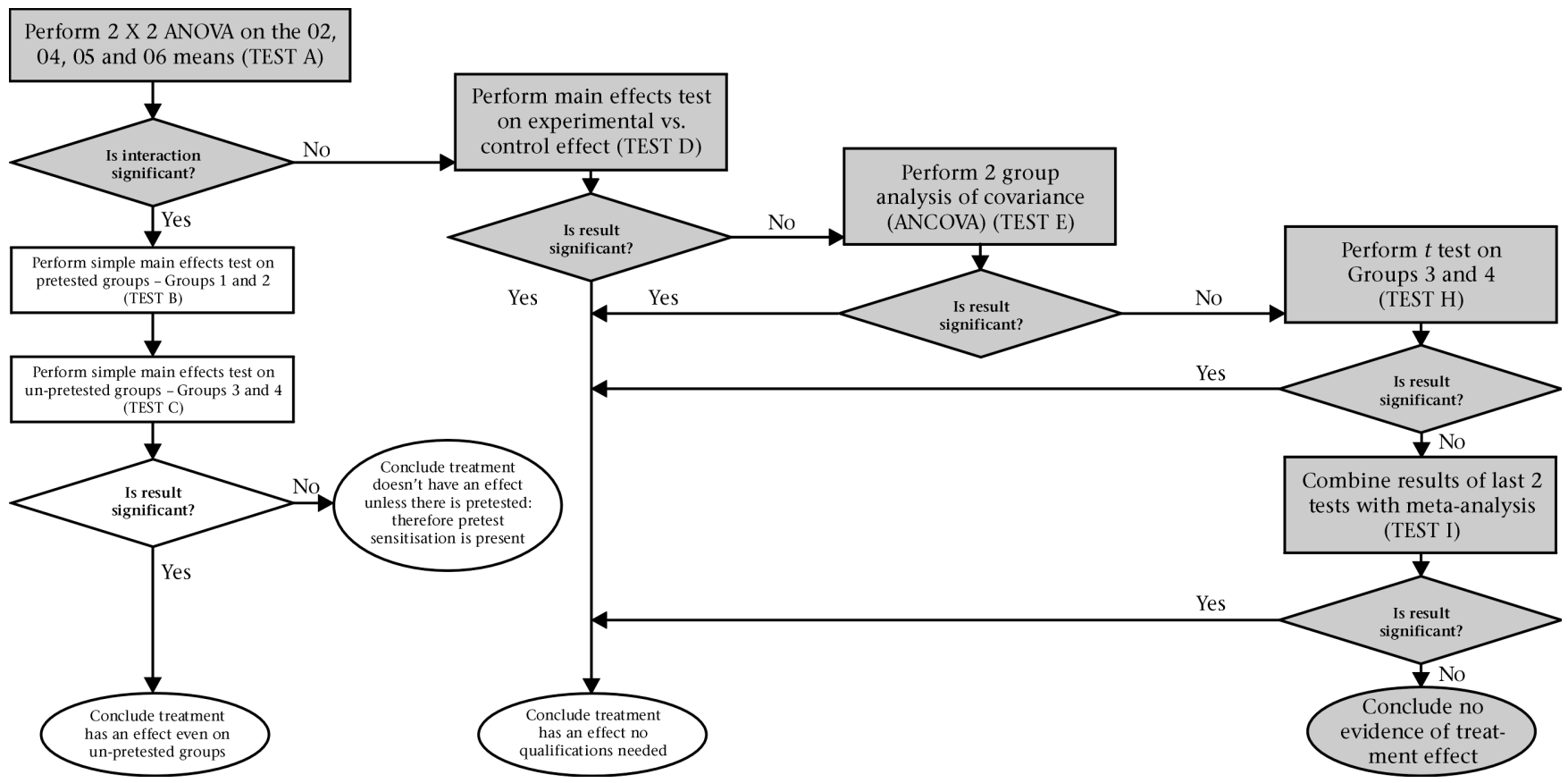

Figure 2: Flowchart of tests conducted and conclusions made to achieve results (Braver \& Braver, 1988, p.152) 
The factors of the ANOVA are treatment (yes versus no) and pretest (yes versus no). Test A was conducted to assess the interaction of these factors, which would determine the absence of pretest sensitisation. The results of the $2 \times 2$ ANOVA are displayed in Table 6 . These results indicate that there is no interaction (Test A), and it can be concluded that there is no pretest sensitisation in this study $(p=0.328$ for Scale 1 and $p=$ 0,822 for Scale 2). The question to be asked at this stage is whether or not there is a treatment effect.

TABLE 6

TEST A - ANOVA SUMmary TABLE FOR INTERACTION BETWEEN TREATMENT AND PRETEST/POSTTEST WITH POSTTEST SCORES AS DEPENDENT VARIABLE

\begin{tabular}{lcccccc}
\hline Source & $\begin{array}{c}\text { Dependent } \\
\text { variable }\end{array}$ & $\begin{array}{c}\text { Sum of } \\
\text { squares }\end{array}$ & $\boldsymbol{d} f \begin{array}{c}\text { Mean } \\
\text { squares }\end{array}$ & $\boldsymbol{F}$ & $\boldsymbol{p}$ \\
\hline $\begin{array}{l}\text { Pretest/Postest by } \\
\begin{array}{l}\text { Experimental/ } \\
\text { Control }\end{array}\end{array}$ & & & & & & \\
& Scale 1 & 1563,94 & 1 & 1563,94 & 0,96 & 0,328 \\
& Scale 2 & 12,51 & 1 & 12,51 & 0,05 & 0,822 \\
\hline
\end{tabular}

To answer this question, one has to consider the main effect for treatment in the above analysis, by performing a main effects test on the experimental versus the control effect (Test $D$ ). That is, does the experimental group differ from the control group regardless of whether or not a pretest was administered? If the result of Test $\mathrm{D}$ is significant, it can be concluded that there is unqualified evidence of a treatment effect, irrespective of the pretest. If the result is not significant, however, it cannot be said with total certainty that there is no treatment effect, because this test is not the most powerful available. This is due to the fact that Test $\mathrm{D}$ does not consider the crucial pretest information available for Groups 1 and 2. The results in Table 7 indicate that the main effect (Test D) is not significant $(p=0,990$ for Scale 1 and $p=$ 0,176 for Scale 2). Therefore it is necessary to test the treatment effect in Groups 1 and 2, the two pretested groups.

TABLE 7

TEST D - MAIN EFFECTS TEST ON THE EXPERIMENTAL VERSUS THE CONTROL EFFECT

\begin{tabular}{lcccccc}
\hline Source & $\begin{array}{c}\text { Dependent } \\
\text { variable }\end{array}$ & $\begin{array}{c}\text { Sum of } \\
\text { squares }\end{array}$ & $\boldsymbol{d f}$ & $\begin{array}{c}\text { Mean } \\
\text { squares }\end{array}$ & $\boldsymbol{F}$ & $\boldsymbol{p}$ \\
\hline $\begin{array}{l}\text { Experimental/ } \\
\text { Control }\end{array}$ & & & & & & \\
& Scale 1 & 0,26 & 1 & 0,26 & 0,00 & 0,990 \\
& Scale 2 & 450,46 & 1 & 450,46 & 1,84 & 0,176 \\
\hline
\end{tabular}

The test used to conduct a separate additional analysis on Groups 1 and 2 could be a two-group analysis of covariance (ANCOVA) on the posttest scores, covarying the pretest scores (Test E); a two-group (independent) $t$ test on the posttest minus the pretest scores (Test F); or a test of the interaction in a $2 \times 2$ ANOVA - the factors being firstly treatment (yes = Group 1 versus No = Group 2) and time (pre versus post); and secondly a repeated measures factor (Test $\mathrm{G}$ ). Research has shown that the outcome of Test $\mathrm{G}$ is identical to Test $\mathrm{F}$, which is the appropriate test of differential treatment effects. However, Test $E$ is the preferred approach due to its greater ability to detect a treatment effect, and is the approach that was used for this study. The results of the ANCOVA (Test E) are tabulated in Table 8 . These results indicate that there is no significant difference ( $p$ $=0.168$ for Scale 1 and $p=0,468$ for Scale 2 ), which means that there was no difference in scores between the experimental and control groups. An independent-samples $t$ test (Test $\mathrm{H}$ ) was subsequently conducted.
TABLE 8

TeST E - TWO-Group ANALYSIS OF COVARIANCE (ANCOVA) ON THE POSTTEST SCORES COVARYING THE PRETEST SCORES

\begin{tabular}{lcccccc}
\hline Source & $\begin{array}{c}\text { Dependent } \\
\text { variable }\end{array}$ & $\begin{array}{c}\text { Sum of } \\
\text { squares }\end{array}$ & $\boldsymbol{d f}$ & $\begin{array}{c}\text { Mean } \\
\text { squares }\end{array}$ & $\boldsymbol{F}$ & $\boldsymbol{p}$ \\
\hline $\begin{array}{l}\text { Experimental/ } \\
\text { Control }\end{array}$ & & & & & & \\
& Scale 1 & 1651,84 & 1 & 1651,84 & 1,92 & 0,168 \\
& Scale 2 & 75,17 & 1 & 75,17 & 0,53 & 0,468 \\
\hline
\end{tabular}

The independent $t$ test on $\mathrm{O}_{5}$ and $\mathrm{O}_{6}$ (Test $H$ ) uses the data of Groups 3 and 4 (the groups that completed a posttest only - see Table 2). This may be the least powerful test of all, since it does not take data from Groups 1 and 2 into account. However, if the test produces significant results, it would indicate unqualified treatment effects, and no further testing is necessary. If results are not significant, further testing is required. The results of Test $\mathrm{H}$ are tabulated in Table 9, and are not significant $(t(147)=-0,83$, $p=0,41$ for Scale 1 , and $t(190)=1,57, p=0,12$ for Scale 2 ).

TABLE 9

TEST H - RESULTS OF THE INDEPENDENT T TESTS FOR SCALES 1 AND 2 A USING POSTTEST RESULTS AS DEPENDENT VARIABLES

\begin{tabular}{llccccccc}
\hline & \multicolumn{2}{c}{$\begin{array}{c}\text { Levene's test } \\
\text { for equality } \\
\text { of variances }\end{array}$} & & & & & \\
\hline & $F$ & $p$ & $t$ & $d f$ & $\begin{array}{c}\text { Two- } \\
\text { tailed } p\end{array}$ & $\begin{array}{c}\text { Mean } \\
\text { difference }\end{array}$ & $\begin{array}{c}\text { Std. error } \\
\text { difference }\end{array}$ \\
\hline $\begin{array}{l}\text { Scale 1 } \\
\text { (Posttest)- }\end{array}$ & $\begin{array}{l}\text { Equal } \\
\text { variance } \\
\text { assumed }\end{array}$ & 0,25 & 0,61 & $-0,83$ & 147 & 0,41 & $-5,35$ & 6,44 \\
\hline $\begin{array}{l}\text { Scale 2 } \\
\text { (Posttest) }\end{array}$ & $\begin{array}{l}\text { Equal } \\
\text { variance } \\
\text { assumed }\end{array}$ & 1,00 & 0,32 & 1,57 & 190 & 0,12 & 3,98 & 2,54 \\
\hline
\end{tabular}

To conclude the process and obtain maximum power, a test is needed at this stage that will combine the test of the treatment in Groups 1 and 2, with the test of the treatment in Groups 3 and 4. Meta-analysis (Test I) can be used to indicate how the results from independent tests of the same hypotheses can be statistically combined, even when the significance tests come from different statistical techniques. Numerous methods are available to achieve this, but Stouffer's $z$ method is recommended by Braver and Braver (1988), as it is the most simplistic. In this approach, the $p$ level from each statistical test is converted to a normal deviate $(z)$ value, and then the $z$ values obtained are combined into a single $z_{\text {meta }}$ using the formula:

$Z_{\text {meta }}=\sum_{i} z_{p i} / \sqrt{ } k$

where $z_{p i}$ is the $z$ value corresponding to the one-tailed $p$ value of the ith statistical test and $\mathrm{k}$ is the number of such tests (Braver \& Braver, 1988, p.152). For this study, $k=2$, so the test reduces to:

$z_{\text {meta }}=\left(z_{p 1}+z_{p 2}\right) / \sqrt{ } 2$

where $z_{p 1}$ is the $z$ value corresponding to the one-tailed $p$ value of Test $\mathrm{E}$, and $z_{p 2}$ is the $\mathrm{z}$ value corresponding to the one-tailed $p$ value of Test $\mathrm{H}$. A $z$ table is then referred to for the significance of $z_{\text {meta }}$ (Test I). This is the most powerful single test of the treatment effect available, as it makes use of the data from all four groups.

The results of Test I, which combined the $t$ test result with the ANCOVA result, yielded a meta-analytic result that was not significant $\left(z_{\text {meta }}=1,03 ; p=0,1515\right)$. It can therefore be concluded that there was no evidence of a significant treatment effect. 


\section{DISCUSSION}

The results indicate that the diversity awareness training programme did not have a statistically significant effect on the two scales assessed (namely awareness of diversity and job satisfaction). While the intervention had no effect, the following are possible reasons why no effects were registered:

- Participants were assigned to the experimental and control groups before randomisation was implemented to obtain two experimental and two control groups.

- Due to the nature of the work at the accounting firm, some participants completed the posttest $2-3$ weeks later than they were required.

- The questionnaire may not have effectively measured dimensions that could have changed as a result of the training.

- The training programme was a short course, and may not have maximised experimental variance to a degree required to produce an effect. A longer course may well have proved effective.

Another potential reason why the diversity awareness programme did not produce the desired positive results, is that it was not handled as a change initiative. Managing diversity is directly linked to organisational change. Cox and Beale (1997) provide an effective model for guiding organisational change for managing cultural diversity. This model indicates that education and training is but one initiative in the process to bring about organisational change. Arredondo's research (1996) supports this model, as well as the findings of this study, namely that training as a single-dimension approach is rarely sufficient to address organisational structures and systems that impact diversity.

It is evident that the diversity awareness training programme assessed during this study was not implemented as part of a change process. It is not surprising then that, when a sample of 60 participants from the experimental group was randomly interviewed, individuals expressed a lack of faith in training programmes. While they agreed that training may initiate the process, they expected no follow-up and believed that changes will not be implemented or followed through. It is their perception that senior management does not attend training initiatives, which results in little skill transfer and change in the workplace.

At this point it may be asked why organisations are still relying on training initiatives alone to address the diversity issue, when previous research has indicated that these initiatives will not be successful on their own, and when these initiatives are not producing results to impact on the bottom line. A possible answer to this question could be that managers and human resource professionals are uninformed concerning available research. Another possible answer is that managers are at a loss as to what other initiatives to implement. No research has been conducted in respect of initiatives that effectively address diversity in the workplace in South Africa, and there is no failproof, step-by-step approach that can be followed. A further possibility could be that managers themselves are resistant towards managing diversity, and are using training initiatives as "window dressing" to ward off criticism that nothing is being done in this regard.

A further concern that could have produced these results is that managers/trainers/consultants are not conducting sufficient, indepth needs analyses before creating and implementing training initiatives. As a result, the immediate, day-to-day diversityrelated problems are not being addressed in organisations, and the overall perceptions that individuals have regarding their organisations are not being changed. Examples of these day-today problems include:

- The perceptions of white managers that Black staff are not adequately skilled to enable them to work on jobs of equal quality and standard to their white counterparts. The opinion of Blacks that their managers give them inferior tasks. What may further complicate the issue is white managers sensing resistance on the part of Black staff to attend additional training courses, as they feel they are being discriminated against in this way.

- Black staff feeling insecure as a result of the belief that they are used as window dressing/tokenism to assist in the promotion of their companies.

- Whites harbouring feelings of resentment fuelled by the perception that Blacks have attained certain positions based on their skin colour rather than their skills and competencies. Conversely, Black staff harbouring feelings of resentment fuelled by the perception that they are not given the same advancement opportunities as their white counterparts. This fuels the opinion that Blacks may have that discriminatory stereotypes still exist, especially in terms of standards, quality of work, and ability.

- The view held by Blacks that their culture will always appear to be foreign in the world of work, and that they are required to change and adapt.

- A perception amongst both Blacks and whites that management and or colleagues are not committed to diversity and change initiatives, and that double standards apply in organisations.

It is understandable how these issues, if not managed adequately, may lead to feelings of resentment, mistrust, anger, frustration and helplessness for all those concerned (Black and white). It is unrealistic to expect diversity initiatives to work when participants are still harbouring these feelings. Based on cognitive theory, behavioural changes can only be addressed once cognitive change has occurred. Until these issues and negative mindsets are addressed and openly discussed, possibly as a training initiative, it would be expected that any other training undertaken (like diversity awareness training) will not achieve the desired results. Participants (no matter how positive after the diversity awareness training programme) will simply return to an environment where they feel they are discriminated against, and what was achieved during the training will soon be forgotten. A solution has to be found.

Diversity can only be respected and effectively managed in an organisation if all employees are actively participating in the process (Hayles \& Russell, 1997). This study supports the opinion of Carnevale and Kogod (1996), namely that training alone cannot ensure the continued valuing and managing of diversity.

Diversity appears to be a sensitive issue in the majority of organisations. There is an ever increasing need for practitioners in the field to familiarise themselves with regards to diversity issues, and be comfortable speaking openly about addressing these. More research is necessary to identify training (and other) initiatives that will effectively begin to address the day-to-day diversity issues and bring about change for the better.

There is a pressing need to effectively manage diversity within organisations in order to maximally contribute towards achieving organisational goals and objectives. Managing diversity should be an ongoing process. Arredondo (1997) provides guidelines that practitioners in the field should use to ensure that training initiatives (including diversity awareness training) are part of a process rather than an event. It is necessary to first develop training goals based on the mission of the diversity initiative to promote relevance and context. Once this has been achieved, formal presentations/orientation sessions should be implemented by management to staff with the aim of explaining the rationale for the programme. This will enhance buy-in and commitment. The next step would be to integrate actual business concerns and goals into the training. This will make the programme organisation-specific, and will assist in addressing the day-to-day diversity concerns. It is then essential to get participants (both senior staff and employees) to complete an action plan, highlighting specific activities that will enable the application of the material covered in the programme. This will ensure that what is learned will be transferred into the 
workplace. Finally, participants should be encouraged to evaluate the training programme, informing trainers of the strengths and limitations of the content, process, methodology and so forth. The issue of confidentiality is essential at this point to ensure that participants feel free to comment openly and honestly about the programme.

In conclusion, Human (1996) identifies three major challenges with regards to the management of diversity: the management of universalistic (maximalist) and particularistic (minimalist) perspectives; the control of negative expectancy communications associated with stereotypes; and turning around individuals who are still holding on to traditional forms of power and control. It appears that to bring about cognitive, conative and eventually affective change, training alone will not adequately address these challenges, and is only a small part of the process. It is thus the role of the organisation to provide opportunities for individuals to change, and create organisational pressure for them to do so. Organisations may further empower individuals most affected by negative stereotyping to affirm their individuality and strengths. More research is necessary to identify specific interventions (of which diversity awareness training may most certainly be one) that will assist in achieving these objectives. Once the challenges of diversity have been recognised and accepted, the potential for the effective management of individuals in organisations can be created.

\section{REFERENCES}

Arredondo, P. (1996). Successful diversity management initiatives: A blueprint for planning and implementation. London: Sage.

Baron, A. (1998). Top managers still don't get it. Across the Board, 35 (7), 22.

Barry, B. \& Bateman, T.S. (1996). A social trap analysis of the management of diversity. Academy of Management Review, 21 (3), 757-790.

Beekie, R. (1997). Diversity training's big lie. Training, 34 (2), 122.

Braver M.C.W \& Braver, S.L. (1988). Statistical treatment of the Solomon four-group design. Psychological Bulletin, 104 (1), 150-154.

Brown, T. (1998). From working wounded to working joyfully. Across the Board, 35 (8), 24-29.

Campbell, D. \& Stanley, J. (1963). Experimental and quasiexperimental designs for research. Chicago: Rand McNally.

Carnevale, A.P. \& Kogod, S.K. (1996). Tools and activities for a diverse workforce. New York: McGraw-Hill.

Chatman, J.A., Polzer, J.T. \& Neale, M.A. (1998). Being different yet feeling similar: The influence of demographic composition and organizational culture on work processes and outcomes. Administrative Science Quarterly, 43 (12), 749-780.

Clarke, C. (1994). Making diversity more manageable. Training and Development, 48 (9), 53-56.

Cox, T. (1997). Linkages between managing diversity and organisational performance. In T. Cox and R.L. Beale (Eds.). Developing competency to manage diversity: Readings, cases and activities. San Francisco: Berrett-Koehler (pp 35-47).

Cox, T \& Beale, R.L. (1997). Developing competency to manage diversity: Readings, cases and activities. San Francisco: Berrett-Koehler.

Cox, T. \& Finley-Nickelson, R. (1997) The process of acculturation in diverse organisations. In T. Cox \& R.L. Beale (Eds.). Developing competency to manage diversity: Readings, cases and activities. San Francisco: Berrett-Koehler (pp 203213).

Cox, T. \& Nkomo, S. (1996). Race and ethnicity. In M.C. Gentile (Ed.). Managerial excellence through diversity. Chicago: Irwin.

Davis, J. \& Rodela, E.S. (1997). Mentoring for the Hispanic. In T. Cox \& R.L. Beale (Eds.). Developing competency to manage diversity: Readings, cases and activities. San Francisco: BerrettKoehler.
Day, L.E.O. (1995). The pitfalls of diversity training. Training and Development, 49 (12), 25-29.

De Anda, D. (1997). Bicultural socialization: Factors affecting the minority experience. In T. Cox \& R.L. Beale (Eds). Developing competency to manage diversity: Readings, cases and activities. San Francisco: Berrett-Koehler (pp. 214-235).

Diamante, T., Reid, C.L. \& Giglio, L. (1995). Making the right training move. HR Magazine, 40 (3), 60-63.

Editor a. (1995). Diversity: Getting past stereotypes. Supervisory Management, 40 (8), 1-6.

Editor b. (1995). Is HRD bogus? Training and Development, 49 (7), 20.

Editor. (1997). Succeeding with teams. Technology Management, $40(4), 56-57$.

Egge, S.A.M. (1999). Creating an environment of mutual respect within the multicultural workplace both at home and globally. Management Decision, 37 (1), 24-28.

Foty, T. (1995). Quick-fix diversity efforts are doomed. Training, $32(1), 18-19$

Fritz, J.H. (1997). Men's and women's organizational peer relationships: A comparison. Journal of Business Communication, 34 (1), 27-46.

Gordon, J. (1995). Different from what? Diversity as a performance issue. Training, 32 (1), 25-32.

Greenhaus, J.L. \& Callanan, G.A. (1994). Career management ( $2^{\text {nd }}$ ed.). Fort Worth: Dryden.

Griggs, L.B.B. \& Louw, L.L. (1995). Diverse teams: Breakdown or breakthrough? Training and Development, 49 (10), 22-29.

Hayes, D.H. \& Hollman, K.W. (1996). Managing diversity: Accounting firms and female employees. CPA Journal, 66 (5), 36-39.

Hayles, V.R. \& Russell, A.M. (1997). The diversity directive: Why some initiatives fail and what to do about it. Chicago: Irwin.

Hermon, M.V. (1996). Building a shared understanding and commitment to managing diversity. Journal of Business Communication, 33 (4), $427-442$.

Hickman, G.R. \& Creighton-Zollar, A. (1998). Diverse selfdirected work teams: Developing strategic initiatives for 21st century organisations. Public Personnel Management, 27 (2), 187-200.

Hopkins, W.E. (1997). Ethical dimensions of diversity. London: Sage.

Huck,S \& Sandler, H.M. (1973). A note on the Solomon fourgroup design: Appropriate statistical analyses. Journal of Experimental Education, 42 (1), 54-55.

Human, L. (1996). Competencies for managing diversity: what South African managers need. In M.E. Steyn. and K.B. Motshabi, (Eds.). Cultural synergy in South Africa (pp171183). Randburg, Johannesburg: Knowledge Resources.

Human, L. (1996). Contemporary Conversations: Understanding and managing diversity in the modern world. Ndabeni, Western Cape: Rustica.

Huysamen, H.K. (1994). Methodology for the social and behavioural sciences. Halfway House, South Africa: Southern.

Innes, D., Kentridge, M.L. \& Perdd, H. (1993). Reversing discrimination: Affirmative action in the workplace. Cape Town: Oxford University.

Joinson, C. (1995). Cultural sensitivity adds up to good business sense. HR Magazine, 40 (11), 82-84.

Kikoski, J.F. (1998). Effective communication in the performance appraisal interview: Face-to-face communication for public managers in the culturally diverse workplace. Public Personnel Management, 27 (4), 491-513.

Kerlinger, F.N. \& Lee, H.B. (2000). Foundations of behavioral research (4th ed.). New York: Harcourt.

Koonce, R. (1997). You can whine or you can shine. Training and Development, 51 (5), 24.

Laabs, J.J. (1995). Does image matter? Personnel Journal, 74 (12), 48-61.

Laird, D. (1985). Approaches to training and development (2nd ed.). Reading, Massachusetts: Addison-Wesley.

Leedy, P.D. (1993). Practical research: planning and design (5 $5^{\text {th }}$ ed.). New York: Macmillan. 
Lubinski, D. \& Dawis, R.V. (1994). Assessing individual differences in human behavior. California: Davies-Black.

Mathews, A. (1998). Diversity: A principle of human resource management. Public Personnel Management, 27 (2), 175-185.

Markoczy, L. (1998). Us and them. Across the board, 35 (2), 44-48.

Martinez, M. (1997). Work-life programs reap business benefits. HR Magazine, 42 (6), 110-114.

Mendzela, E. (1997). Effective teams. CPA Journal, 67 (9), 62-63.

Miller, F.A. (1998). Strategic culture change: The door to achieving high performance and inclusion. Public Personnel Management, 27 (2), 151-160.

Milliken, F.J. \& Martins, L.L. (1996). Searching for common threads: Understanding the multiple effects of diversity in organisational groups. Academy of Management Review, 21 (2), 402-433.

Morris, B. (1997). Is your family wrecking your career (and vice versa)? Fortune, 135 (3), 71-90.

Norton, T.R. \& Fox, R.E. (1997). The change equation: Capitalizing on diversity for effective organizational change. Washington, DC: American Psychological Association.

Parkinson, D. (1997). Do childless employees have a beef? Across the Board, 34 (9), 56.

Parkinson, D. (1998). What the least-paid need most. Across the Board, 35 (5), 55.

Paskoff, S.M. (1996). Ending the workplace diversity wars. Training, 33 (8), 42-47.

Patterson, C.H. (1986). Theories of counseling and psychotherapy ( $4^{\text {th }}$ ed.). New York: Harper \& Row.

Rodwell, J.J., Kienzie, R. \& Shadur, M.A. (1998). The relationships among work-related perceptions, employee attitudes, and employee performance: The integral role of communication. Human Resource Management, 37 (3-4), 277-293.

Rosen, B. \& Lovelace, K. (1994). Fitting square pegs into round holes. HR Magazine, January, 86-93.

Rosenthal, R. \& Rosnow, R.L. (1991). Essentials of behavioural research: Methods and data analysis. (2nd ed.). New York: McGraw-Hill.
Rynes, S. \& Rosen, B. (1994). What makes diversity programmes work? HR Magazine, 39 (10), 67-68.

Schor, S.M. (1997). Separate and unequal: The nature of women's and men's career-building relationships. Business Horizons, 40 (5), 51-57.

Schreiber, E.J. (1996). Muddles and huddles: Facilitating a multicultural workforce through team management theory. Journal of Business Communication, 33 (4), 459-473.

Settle-Murphy, N.M. (1996). Preventing cultural differences from undermining your global projects. Information Strategy: The Executives Journal, 13 (1), 37 - 48.

Slobodnik, D. \& Slobodnik, A. (1996). The team killers. HR Focus, 73 (6), 22-23.

Smith, K. \& Berg, D. (1997). Cross-cultural groups at work. European Management Journal, 15 (1), 8-15.

Spiegler, M.D. (1983). Contemporary behavioral therapy. California: Mayfield.

Thomas, V.C. (1994). The downside of diversity. Training and Development, 48 (1), 60-62.

Tietjen, M.A. \& Myers, R.M. (1998). Motivation and job satisfaction. Management Decision, 36 (4), 226-231.

Tsukudu, T. (1996). Mentoring for career advancement in South Africa. People Dynamics, 14 (4), 13-18.

Van Buren, H.J. (1997). Ending the culture of corporate discrimination. Business and Society Review, 98, 20-23.

Van Eron, A.M. (1995). Ways to assess diversity success. HR Magazine, 40 (8), 51-52.

Wanguri, D.M. (1996). Diversity, perceptions of equity, and communicative openness in the workplace. Journal of Business Communication, 33 (4), 443-457.

Weiten, W. (1983). Psychology: Themes and variations. Pacific Grove, California: Brooks/Cole.

Welman, J.C. \& Basson, P.A. (1995). The interrelationship between the work experience of distance education students, job satisfaction, and academic achievement. Journal of Industrial Psychology, 21 (1), 14-17.

Whitehead, M. (1998). Employee happiness levels impact on the bottom line. People Management, 4 (24), 14. 